BNL 50533

(Particle Accelerators and High-Voltage Machines - TID 4500)

\title{
ELECTRON CLEARING FOR THE ISA PROTON BEAM
}

\author{
J. C. Herrera
}

July 12, 1976

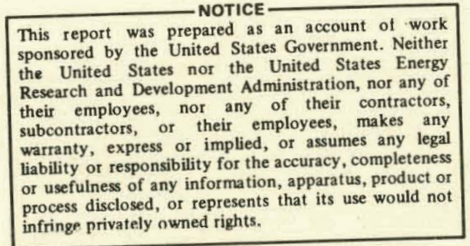

ACCELERATOR DEPARTMENT

B R O O K H A V EN N A T I ONA L I A B O R A T O R Y A S S OC I A TE D UNIVERS I T I ES, INC.

U P T O N, NE W Y OR K 11973

under contract No. $E(30-1)-16$ with the

UNITED STATES ENERGY RESEARCH AND DEVELOPMENT ADMINISTRATION 


\section{DISCLAIMER}

This report was prepared as an account of work sponsored by an agency of the United States Government. Neither the United States Government nor any agency Thereof, nor any of their employees, makes any warranty, express or implied, or assumes any legal liability or responsibility for the accuracy, completeness, or usefulness of any information, apparatus, product, or process disclosed, or represents that its use would not infringe privately owned rights. Reference herein to any specific commercial product, process, or service by trade name, trademark, manufacturer, or otherwise does not necessarily constitute or imply its endorsement, recommendation, or favoring by the United States Government or any agency thereof. The views and opinions of authors expressed herein do not necessarily state or reflect those of the United States Government or any agency thereof. 


\section{DISCLAIMER}

Portions of this document may be illegible in electronic image products. Images are produced from the best available original document. 


\section{NOT I C E}

This report was prepared as an account of work sponsored by the United States Government. Neither the U.S. nor the U.S. Energy Research and Development Administration, nor any of their employees, nor any of their contractors, subcontractors, or their employees, makes any warranty, express or implied, or assumes any legal liability or responsibility for the accuracy, completeness or usefulness of any information, apparatus, product or process disclosed, or represents that its use would not infringe privately owned rights.

$$
\begin{gathered}
\text { PRINTED IN THE UNITED STATES OF AMERICA } \\
\text { Available from } \\
\text { National Technical Information Service } \\
\text { U.S. Department of Commerce } \\
\text { 5285 Port Roya } 1 \text { Road } \\
\text { Springfield, VA } 22161
\end{gathered}
$$

Price: Printed Copy $\$ 3.50$

; Microfiche $\$ 2.25$ 


\section{ABSTRACT}

The circulating protons in the ISABELLE intersecting storage ring accelerator will collide with the residual gas in the vacuum chamber. The electrons produced will tend to be captured by the potential well of the beam itself and result in a neutralization of the space charge of the beam. In this report we analyze in some detail the various mechanisms which can be used to reduce the net degree of beam neutralization. We conclude that the average neutralization will be about $10^{-4}$ for a residual gas pressure of $3 \times 10^{-11}$ Torr of hydrogen. 


\section{Introduction}

It is planned to have the vacuum chamber of the intersecting storage accelerator, ISA, operate at room temperature with a pressure of about $3 \times 10^{-11}$ Torr. Under these conditions the residual gas will be predominantly hydrogen with a density of $10^{6}$ molecules $/ \mathrm{cm}^{3}$. The proton beam of $10 \mathrm{~A}$, that is, a stored beam of $6 \times 10^{14}$ protons, will undergo collisions with the residual gas. Though the beam-size growth and background radiation accompanying this scattering are very small, ' the products of these collisions, ions and electrons, may have a deleterious effect on the stability and lifetime of the circulating proton beam. The ions, for example, when accelerated toward the chamber wall by the radial field of the beam may desorb other ions from the wall surface, and, if such a process becomes cumulative, the accompanying pressure rise will result in a loss of beam. This "pressure bump phenomena" has been discussed elsewhere. ${ }^{2}$ The freed electrons, instead, are not driven toward the chamber wall, but tend to be captured by the attractive potential of the positively charged beam. The result is a neutralization of the space charge of the beam and a resultant shift in the betatron tunes. This effect has been studied in some detail for the ISABELLE machine in Ref. 3. In the present report we shall investigate the production and trapping of electrons in the ISA beam and the extent to which Lhese electrons can be removed from the beam, that is, cleared.

\section{Beam Potential to the Wall}

The proton beam cross section in ISABELLE 1s sma11. For the maximum stored current (I) of $10 \Lambda$ the elcctrootatic potential between the beam and the chamber wall will therefore be large.

1. A Proposal for Construction of a Proton-Proton Storage Accelerator Facility, BNL 20161, June 1975.

2. H.J. Halama and J.C. Herrera, IEEE Trans. Nucl. Sci. NS-22, No. 3, 1492 (1975).

3. A.W. Chao, J.C. Herrera, and M. Month, Proc. of the 1975 ISABELLE Summer Study, BNL 20550, 418. (1975). 
If we assume a cylindrical geometry with a circular beam of diameter (2a) centrally located in a circular chamber of diameter $D$, we have for the potential $\mathrm{V}$ :

$$
V=\frac{I}{2 \pi \epsilon_{0}^{c}} \ln \left(\frac{D}{2 a}\right)
$$

In this equation SI units are used. Inserting a typical value of $a=1.4 \times 10^{-3} \mathrm{~m}$ and the chamber diameter of $8 \times 10^{-2} \mathrm{~m}$, we obtain a potential of $2 \mathrm{kV}$. Singly charged positive ions produced in the residual gas will therefore strike the envelope wall with a kinetic energy of $2 \mathrm{keV}$, while electrons which have an energy smaller than this value will be trapped inside the beam.

\section{Production Rate of Electrons}

The principal process occurring in the residual gas of a storage ring is ionization of the atoms by the circulating protons. The energy lost by the proton and the associated production of free electrons have been studied by K. R. Simon and others. ${ }^{4,5}$. For the production rate of electrons, $R_{p}$, (per second and per circulating proton) which have an energÿ less than the trapping potential $V$ of the beam, they find

$$
R_{p}=2 \pi r^{2} m c^{3} \frac{N Z}{V_{0}}\left[\ln \left(\frac{2 m c^{2} \gamma^{2} V}{E_{I}^{2}}\right)-1\right],
$$

where:

$$
\begin{aligned}
\mathrm{N}= & \text { atomic density of gas (atoms } \left./ \mathrm{cm}^{3}\right) \\
\mathrm{Z}= & \text { atomic number of gas } \\
\mathrm{r}_{\mathrm{e}}= & \text { classical electron radius }\left(2.818 \times 10^{-13} \mathrm{~cm}\right) \\
\mathrm{mc}^{2}= & \text { rest mass energy of electron }\left(0.511 \times 10^{6} \mathrm{eV}\right) \\
\mathrm{V}_{\mathrm{O}}= & \text { average energy for the formation of an ion-electron pair } \\
& (36 \mathrm{eV}) \\
Y= & \text { relativistic gamma of incident proton } \\
\mathrm{E}_{I}= & \text { average atomic ionization energy }(=13.5 \mathrm{Z}, \mathrm{eV}) \text {, and } \\
\mathrm{c}= & \text { velocity of light }\left(2.998 \times 10^{10} \mathrm{~cm} / \mathrm{sec}\right) .
\end{aligned}
$$

4. B. Angerth, AR/Int. SG/65-1, (1965).

5. 0. Grobner, CERN/ISR-AS/74-67 (1974). 
Since at room temperature $(293 \mathrm{~K}$ ) and a pressure of $\mathrm{P}$ (Torr), the number of atoms per cubic centimeter in a diatomic gas is

$$
\mathrm{N}=6.579 \times 10^{16} \mathrm{P} \text {, }
$$

Eq. 3 can be written as

$$
R_{p}=1.434 \times 10^{7} \mathrm{zP}\left[\ln \left(5608 \frac{\gamma^{2} V}{z^{2}}\right)-1\right]
$$

For a beam at full energy $(\gamma=213)$ and a residual hydrogen gas at $3 \times 10^{-11}$ Torr, we calculate that the production rate of trapped electrons is $11 \times 10^{-3}$ electrons/sec for every proton. Hence with no clearing mechanism the number of electrons would equal the number of protons in nearly $100 \mathrm{sec}$, that is, the beam space charge would be completely neutralized in this time. We note that, because of the logarithmic dependence on $\gamma$, the electron production rate is rather insensitive to beam energy. For example, at the injection energy $(\gamma=31.4)$ this rate is equal to $9.5 \times 10^{-3} / \mathrm{sec}$.

\section{Degree of Neutralization and Clearing Rate}

The equilibrium degree of neutralization; defined as the ratio, $\eta$, of free electrons to beam protons, will depend on the production rate, $R_{p}$, calculated in the last section and the electron clearing rate $R_{c}$. Thus, under equilibrium conditions, the balance between the production and clearing of electrons is expressed as ${ }^{6}$

$$
R_{p} N_{p}-R_{c} N_{e}=0
$$

and the beam neutralization can then be written as the ratio

$$
\eta=\frac{N_{e}}{N_{p}}=\frac{R_{p}}{R_{c}} \text {. }
$$

We observe that for a neutralization of $10^{-4}$, a value which wlll be shown to be reasonably achievable for ISABELLE, the required clearing rate, $R_{c}$, implied by Eq. 6 is $100 / \mathrm{sec}$.

6. B. Angerth, E. Fisher, and 0 . Gröbner, Proc. of the 8th Int. Conf. on High Energy Accelerators, CERN (1971), p. 298 . 


\section{Clearing Rate due to Beam Heating and Single Scattering}

The energy which must be acquired by an electron in order to escape from the beam attractive potential can be given to it in a single scattering or as the result of multiple scattering, that is beam heating. Though both of these processes yield too small a clearing rate to be relied on to provide adequate clearing in the ISA, we shall in this section, for the sake of completeness, estimate their magnitude.

The clearing rate due to beam heating is expressed by the relation ${ }^{5}$

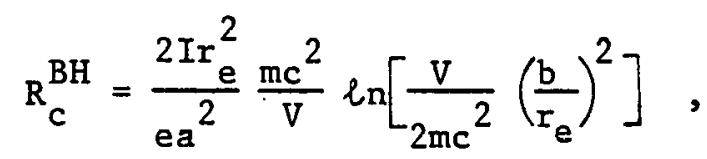

where the new symbols are e for the electron charge (Coulomb), and $b$ for the maximum impact parameter $(\mathrm{cm})$. Assuming $b$ to have the largest possible value equal to the chamber radius, we find that the electron clearing rate due to beam heating, $\mathrm{R}_{c}^{\mathrm{BH}}$, is about $7 / \mathrm{sec}$.

As would be expected, the clearing rate due to single scattering is less than that due to beam heating. As shown by Gröbner, ${ }^{5}$ the single scattering clearing rate is essentially equal to the cuefficient of the logarfthiu in Eq. 7, and thio implies an elertron clearing rate of $\mathrm{R}_{\mathrm{c}}^{\mathrm{SS}}=0.1 / \mathrm{sec}$.

In short, if we combine the two mechanisms for transverse clearing considered in thls section, we havc only about $7 \%$ of that desired to achieve a net neutralization of $10^{-4}$.

\section{Eloctris Field Within a Rectangular Beam}

In order to determine the longitudinal clearing that can be achieved in the ISA, it is first necessary to consider the electric field within the beam proper. This space-charge aspect of the problem has been discussed in some detail in a previous report. 7

7. J.C. Herrera, ISA Report 75-7 (1975). 
Considering Figs. 3 and 4 and the pertinent equations presented therein', we see that the transverse electric field over the beam cross section is essentially given by

$$
E_{x} \simeq \frac{\lambda_{L} G}{2 \pi \varepsilon_{0} a} \frac{x}{a},
$$

where $\lambda_{L}$ is the charge per unit longitudinal length, and the mean gradient function, $G$, takes on the value of about 0.9 for a beam that has a width to height ratio of $\rho=3$. Hence the electric field can be assumed to increase linearly from the beam center to its edge.

VII. Clearing in ISA Dipoles

It is planned ${ }^{1}$ to have a pair of clearing electrodes at each end of the ISA dipole magnets. The electrostatic potential between the pair of electrodes will be sufficient $(\sim 10 \mathrm{kV})$ to extract the electrons which arrive at the azimuthal position of these electrodes. Because of the magnetic field present in the dipoles, however, the trapped electrons tend to travel in small circular trajectories normal to the direction of the field. Thus, at a magnetic field of 4 tesla and a kinetic energy of $2 \mathrm{keV}$, an electron will follow a path having a small radius equal to $4 \times 10^{-3} \mathrm{~cm}$. In order to move the electrons longitudinally along the beam toward the clearing electrode, it is therefore necessary to rely on the longitudinal ( $E \times B$ ).drift, where in this case the $E$ field arises from the space charge of the beam. Accordingly, we can write for the drift velocity of an electron at a distance, $x$, from the center of the beam the expression:

$$
v^{D}(x)=\frac{E}{B}=\frac{\lambda_{L} G}{2 \pi \varepsilon_{0}{ }^{a B}} \frac{x}{a} .
$$

The corresponding clearing rate for a dipole of length I is then

$$
R_{c}^{D}(x)=\frac{v^{D}(x)}{L}
$$


Since at the very center of the proton beam $(x=0)$ the clearing rate vanishes, we now assume a model in which the beam is completely neutralized within a small central region defined by $|x|<a_{0}$, that is, the number of free electrons is equal to the number of protons. One can then write for the total number of electrons $\left(\mathrm{N}_{e}\right)$ in the beam of width (2a) the relationship

$$
N_{e}=N_{p} \frac{a}{a}+\int_{a_{0}}^{a} n_{e}(x) d x
$$

The quantity $\mathrm{n}_{e}(\mathrm{x})$ is the electron density at a distance $x$ from the center of the beam; and under equilibrlum conditions it is related to the proton number according to

$$
R_{p} N_{p} \frac{d x}{a}-R_{c}^{D}(x) n_{e}(x) d x=0
$$

Using Eqs. 9 and 10, we evaluate the integral in Eq. 11, and obtain the overall degree of neutralization

$$
\frac{N_{e}}{N_{p}}=\frac{a_{0}}{a}\left[1+\frac{R_{p} L}{v D_{(a)}} \frac{a}{a_{0}} \cdot \ln \left(\frac{a}{a_{u}}\right)\right] \text {. }
$$

In the model we are conslderluy of a beam chat lu not cloaren in a central region extending to a small distance $a_{0}$, Eq. 13 represents a condition on the ratio $\left(a / a_{0}\right)$. If this ratio is such that the second term in the parenthesis is small compared to unity, then the avcrago noutralization of the beam will be

$$
\eta_{n}=\frac{\mathrm{N}_{\mathrm{e}}}{\mathrm{N}_{\mathrm{p}}} \approx \frac{\mathrm{a}_{0}}{\mathrm{a}}
$$

If we now impose the requirement that this term contribute only a magnitude of $(1 / 10)$, we thereby derive the transcendental equation

$$
\frac{1}{\eta_{D}} \ln \left(\frac{1}{\eta_{D}}\right)=\frac{1}{10}\left(\frac{v^{D}(a)}{R_{p} L}\right)
$$


for the average beam neutralization $\eta_{D}$ in the dipoles.

For the ISA at high energy, we select the following numerical values :

$$
\begin{aligned}
B & =4 \mathrm{~T}, \\
L & =4.5 \mathrm{~m}, \\
a & =0.5 \times 10^{-2} \mathrm{~m}, \\
G & \approx 0.9(\text { for } \rho=3), \\
\lambda_{L} & =3.34 \times 10^{-8} \mathrm{c} / \mathrm{m}, \text { and } \\
R_{P} & =11 \times 10^{-3} / \mathrm{sec} .
\end{aligned}
$$

Equation 9 now yields the drift velocity of the beam outer edge, $\mathrm{v}^{\mathrm{D}}(\mathrm{a})$, of $27 \times 10^{3} \mathrm{~m} / \mathrm{sec}$, and the associated average neutralization in the dipole magnets is, per Eq. $15,1.6 \times 10^{-4}$.

At injection field $(0.59 \mathrm{~T})$ the beam horizontal size is larger $\left(a \simeq 1 \times 10^{-2} \mathrm{~m}\right)$ than it is at high field. Corresponding to these values, the maximum drift velocity and the neutralization are respectively $90 \times 10^{3} \mathrm{~m} / \mathrm{sec}$ and $5 \times 10^{-5}$.

\section{Clearing in the ISA Quadrupoles}

The magnetic field in the quadrupoles will tend to trap low energy electrons within the beam. However, in addition to some contribution from the cross drift clearing mechanism, which has been discussed for the dipoles, there is a gradient drift mechanism in the quadrupoles. In this section we shall give an estimate of this longitudinal gradient drift.

According to spitzer, a particle of energy $W(e V)$ in a magnetic field $B$ (tesla), having a gradient $(d B / d r)$ at right angles to the field, will experience a longitudinal drift velocity (m/sec)

$$
v_{L}=\frac{1}{B^{2}} \frac{d B}{d r} W \text {. }
$$

8. I. Spitzer, Jr.,"Phyøica of Tully Iunized Gases", Interscience Publishers, Inc., 1956. 
At full energy the gradient in the cell quadrupoles is $66.4 \mathrm{~T} / \mathrm{m}$. If we consider a trapped particle of thermal energy $(0.04 \mathrm{eV})$ and a beam with a total width of $1 \times 10^{-2} \mathrm{~m}$, we obtain an average axial drift of $96 \mathrm{~m} / \mathrm{sec}$. For a quadrupole length of $1.16 \mathrm{~m}$, we, therefore, have an electron clearing rate of about $83 / \mathrm{sec}$.

The insertion quadrupoles of ISABELLE, Q1 and Q2, have a gradient of $30 \mathrm{~T} / \mathrm{m}$ and a length of about $3 \mathrm{~m}$. The associated longitudinal drifts and clearing rate are respectively $213 \mathrm{~m} / \mathrm{sec}$ and $70 /$ sec.

We would like to point out that in making these estimates we have used the average magnitude of the magnetic field on either side of the central axis of the quadrupoles. Actually electrons produced very near this central axis will be free to move longitudinally as they would do in the straight sections.

\section{Clearing of the Straight Sections}

The ISABELLE doeign calls for plaring clearing electrodes at approximate $30 \mathrm{~m}$ intervals in the straight sections. The absence of a confining magnetic field will hence allow the electrons of luw encrgy to move longitudingly alnng the beam and then be captured by the clearing field. Some idea of the effectiveness of this arrangement can be learned by considering an electron of

thermal energy, $0.04 \mathrm{eV}$. The velocity is then about $10^{5} \mathrm{~m} / \mathrm{sec}$ and the associated clearing rate is consequently about $3000 / \mathrm{sec}$. This large value indicates that any mechanism, such as beam heating, which gives the electrons a slight energy w1ll result in the efficiont longitudinal clearing of the straight sections.

\section{Clearing due to Beta Function Variation}

As has been discussed in the previous sections, electron clearing of the beam is best achieved by causing the electrons to move longitudinally toward a set of clearing electrodes. A possible voltage gradient capable of producing this type of motion is the longitudinal electric field arising from the variation in 
beam cross section characteristic of AG synchrotrons. Though in the case of the ISA, this mechanism contributes only a small clearing, yet a brief discussion of it may be desirable.

The horizontal size of the beam varies with azimuthal position, $z$, as the square root of the beta function, $\beta(z)$. Hence, we write for the beam half-width, $a(z)$,

$$
a(z)=a_{A v} \sqrt{\frac{\beta(z)}{\beta A v}}
$$

We now assume a variation of the beta function of the form ${ }^{9}$

$$
\beta(z)=\frac{\beta_{A v}}{1-\tau \sin \left(\frac{2 \pi}{L_{S}} z\right)} \text {, }
$$

where $\tau$ depends on the form factor and $L_{s}$ is the length of a basic focusing period. The corresponding transverse electric field in the central region of the beam will then be

$$
E_{x}=\frac{\lambda_{L}}{2 \pi \varepsilon_{0}} \frac{x}{a_{A v}^{2}}\left[1-\tau \sin \frac{2 \pi}{L_{s}} z\right]
$$

Here $\lambda_{I}$ is the proton charge per unit length and $x$ the distance from the beam center. Since, as far as the electromagnetic fields are concerned, stationary conditions exist, $\vec{\nabla} \times \vec{E}=0$, and we thereby deduce that the longitudinal electric field is

$$
E_{z}=-\frac{\lambda_{L}{ }^{\top}}{2 \varepsilon_{0} L_{s}}\left(\frac{x}{a_{A v}}\right)^{2} \cos \left(\frac{2 \pi}{L_{s}} z\right)
$$

It can be seen from this relationship that not only does the longitudinal field vary with azimuth, as expected, but also that its amplitude depends quadratically on the distance from the center of the beam. Hence it is not expected that this type of field could provide clearing for electrons produced close to the center of the beam. Some idea of the magnitude of this effect can be had by considering the following ISA numerical values:

9. J.C. Herrera and M. Month, BNL Accelerator Dept. Internal Report AGS 69-10 (1969). 


$$
\begin{aligned}
\lambda_{L} & =3.33 \times 10^{-8} \mathrm{c} / \mathrm{m}, \\
\tau & =2 / 3, \text { and } \\
L_{S} & \simeq 25 \mathrm{~m} .
\end{aligned}
$$

The amplitude of the longitudinal electric field is then

$$
\left|E_{z}\right|=50\left(\frac{x}{a_{A v}}\right)^{2}, V / m
$$

and for a ratio of $x / a_{A v}$ of $10^{-4}$, one gets a electric field of $0.5 \mu \mathrm{V} / \mathrm{m}$; A imali value.

\section{Summary and Conclusions}

In Table I we present a summary of the calculations which have heen carried out for the clearing of the beam in the ISA. It is important to emphasize that, though we have tried to show the basic methods used in deriving the numerical figures listed, the specific values are estimates, in the sense that the actual clearing will be the result of a complicated combination of the various mechanisms eluvisaged. How vver, on the basis of the tabulated numbers, one can draw two conclusions:

(1) The neutralization within the dipole and quadrupole chambers of the ISABELLE alachine will not be greater than 1 to $2 \times 10^{-4}$ for a residual pressure of $3 \times 10^{-11}$ Torr of hydrogen, and

(2) The regular straight sections will have a neutralization of less than $10^{-4}$ for the same gas pressure.

As a final point, it should be mentioned that in this report we have not considered the experimental chambers. These may require complicated. arrangements and novel cross sectional variations, and consequently they may necessitate the addition of special clearing electrodes in order to eliminate local electron traps.

\section{Acknowledgments}

I would like to thank $H$. Halama and M. Month for numerous discussions. 
TABLE I. SUMMARY OF BEAM CLEARING FOR THE ISA

\begin{tabular}{|c|c|c|c|c|c|c|c|c|}
\hline ELEMENT & ENERGY $r$ & $\begin{array}{c}\text { PRODUCTION } \\
\text { RATE } \\
\mathrm{R}_{\mathrm{p}} / \mathrm{sec}\end{array}$ & $\begin{array}{r}\text { CLEAR ING } \\
\text { MECHANISM }\end{array}$ & $\begin{array}{l}\text { CLEAR ING } \\
\text { RATE } \\
\mathrm{R}_{\mathrm{c}} / \mathrm{sec}\end{array}$ & $\begin{array}{c}\text { DRIFT } \\
\text { VELOCITY } \\
\mathrm{m} / \mathrm{sec}\end{array}$ & LENGTH $\mathrm{m}$ & NEUTRALIZATION & SECTION \\
\hline Dipole & 213 & $11 \times 10^{-3}$ & Field Drift & 69 & $27 \times 10^{3}$ & 4.5 & $1.6 \times 10^{-4}$ & VII \\
\hline Dipole & 31.4 & $9.5 \times 10^{-3}$ & Field Drift & 200 & $90 \times 10^{3}$ & 4.5 & $5 \times 10^{-5}$ & VII \\
\hline Ce11 Quad & 213 & $11 \times 10^{-3}$ & Gradient Drift & 83 & 96 & 1.16 & $1.3 \times 10^{-4}$ & VIII \\
\hline $\mathrm{Q} 1 \& \mathrm{Q} 2$ & 213 & $11 \times 10^{-3}$ & Gradient Drift & 70 & 210 & 3.0 & $1.5 \times 10^{-4}$ & $\operatorname{VIII}$ \\
\hline $\begin{array}{l}\text { Straight } \\
\text { Section }\end{array}$ & 213 & $11 \times 10^{-3}$ & Random Motion & 3300 & $10^{5}$ & 30 & $\left(3 \times 10^{-6}\right)$ & IX \\
\hline-- & 213 & $11 \times 10^{-3}$ & Beam Heating & $\sim 7$ & & & $\left(1.6 \times 10^{-3}\right)$ & V \\
\hline--- & 213 & $11 \times 10^{-3}$ & Single scattering & $\sim 0.1$ & & & $\left(10^{-i}\right)$ & V \\
\hline$--\infty$ & & $11 \times 10^{-3}$ & $\beta$ Function Variation & $\sim 40$ & $\sim 1 \times 10^{3}$ & & $\left(3 \times 10^{-4}\right)$ & $\mathrm{x}$ \\
\hline
\end{tabular}

